\title{
BILINGUISMO E IDENTIDADE: UMA DUPLA CONSTRUÇÃO
}

Bianca Alves Lehmann

\begin{abstract}
RESUMO
Este artigo propóe algumas considerações sobre a constituição identitária de sujeitos bilíngues. A pretensão não é a de apresentar dados referentes a pesquisas de campo, tampouco realizar uma análise profunda dos conceitos discutidos, mas sim refletir, sob a ótica dos Estudos Culturais, acerca da complexidade e tensóes envolvidas na questáo da identidade em sujeitos que utilizam duas ou mais línguas.
\end{abstract}

PALAVRAS-CHAVE: Constituiçãoo identitária; Bilinguismo; Identidade linguística.

\section{Breves considerações sobre bilinguismo}

Tndependentemente da perspectiva a ser considerada (seja linguística, sociolinguística, neurolinguística, psicolinguística ou outras), o bilinguismo, no seu sentido mais amplo, caracteriza a utilização de duas ou mais línguas por um mesmo indivíduo. Além disso, abarca uma definição multifacetada, visto que se trata de uma competência linguística individual que pode ocorrer em diversos níveis e graus. Conforme salientam Hamers e Blanc (2000), além do nível de proficiência nas línguas, dimensões não linguísticas são consideradas para o estudo do bilinguismo: competência relativa, organização cognitiva, idade de aquisição, status sociocultural e identidade cultural do indivíduo. Corroborando essa concepção, Flory e Souza (2009, p. 23) afirmam que características tanto individuais quanto contextuais, como "tempo de exposição a essas línguas, valorização afetiva e 
status atribuído a cada uma dessas línguas, presença ou ausência da segunda língua no ambiente" de convívio, determinam o tipo de bilinguismo a ser desenvolvido por um falante.

Grosjean (1994) salienta que o conceito de bilinguismo está ligado ao uso de duas ou mais línguas ou dialetos pelos sujeitos em suas rotinas. Além disso, para o autor, são levados em consideração desde os sujeitos que utilizam com fluência duas línguas distintas (em termos profissionais: tradutores, intérpretes, professores de língua estrangeira, etc.) até os imigrantes que falam, mesmo com dificuldade, a língua do país onde residem. Dessa maneira, ainda segundo Grosjean, o indivíduo bilíngue não é a soma de dois monolíngues, visto que ele utiliza diferentes línguas conforme suas limitaçóes e de acordo com as necessidades do ambiente. Feitas essas considerações sobre o bilinguismo, partiremos para as consideraçóes sobre os sujeitos bilíngues.

\section{Bilíngues: quem são eles? Quem eles pensam que são?}

Muitos bilíngues não se intitulam assim, pois afirmam não ter domínio da forma gramatical de uma segunda língua $\left(L 2^{1}\right)$. Sabemos que em muitas famílias, principalmente as de descendência estrangeira ou, ainda, as que vivem em comunidades colonizadas, a primeira língua aprendida é justamente a estrangeira - nesses casos, no Brasil, normalmente o português é aprendido na escola. Apesar de esses sujeitos terem aprendido a língua estrangeira na escola da vida (quer dizer: não em uma escola convencional) e saberem se comunicar com clareza, creem que só seriam bilíngues caso tivessem frequentado uma escola de idiomas. O mesmo fato acontece com moradores de cidades de fronteira: muitos dominam tanto a língua do seu país quanto a do país vizinho e, mesmo assim, não se consideram bilíngues por acreditarem que o idioma falado por eles seria uma mescla náo pura de idiomas.

$\mathrm{Na}$ concepção popular, bilíngue é o sujeito que fala perfeitamente duas ou mais línguas com total domínio das regras gramaticais. Contudo, segundo os autores já mencionados, se o sujeito falar com habilidade uma L2, mesmo que não escreva ou leia nesse idioma, ele é considerado bilíngue. Conside-

1 Neste artigo, os termos segunda língua (L2) e língua estrangeira (LE) são entendidos como sinônimos. 
remos outros exemplos: tanto o cidadão que utiliza palavras em uma língua estrangeira (LE) para se comunicar em determinados lugares, mesmo sem ter total domínio dessa língua - os brasileiros, por exemplo, que vão até as cidades de fronteira com o Uruguai para fazer compras e conseguem estabelecer a comunicação em espanhol -, quanto o estudante que lê em língua estrangeira e escreve abstract e résumé $e^{2}$ para seus trabalhos científicos, porém não possui a habilidade da fala, são bilíngues.

Tussi e Ximenez (2010) argumentam que diversas são as situações que podem levar um indivíduo a ter contato com duas ou mais línguas e a usá-las em diferentes níveis de competência. Segundo os autores,

a questão [do bilinguismo] é de grau. E é essa questão que está presente nos estudos acerca do bilinguismo. Para Bloomfield, em 1933, o bilinguismo resultaria da adição de um conhecimento perfeito de uma língua estrangeira. Weinreich, em 1953, disse que o bilinguismo seria o uso alternado de duas línguas. Já Haugen, também em 1953, defendia que o bilinguismo começaria com a habilidade de produzir sentenças completas e com sentido na segunda língua (EDWARDS, 2006). Com a ideia de Haugen, até mesmo o mero uso do c'est la vie, por exemplo, poderia ser considerado bilinguismo (TUSSI; XIMENEZ, 2010, p. 2, grifos dos autores).

Diversos autores elencam diferentes classificações, segundo critérios específicos, para definir bilinguismo. A título de conhecimento, as denominaçóes utilizadas por Hamers e Blanc (2000), de acordo com determinadas dimensões, serão apresentadas. Entretanto, vale ressaltar que a discussão em relação às definições e em relação ao grau e às funçôes do bilinguismo ${ }^{3}$ não será aprofundada; apenas será ilustrada em um breve esquema, conforme mostra o Quadro 1.

2 Ambos os termos são traduções, em inglês e francês, respectivamente, da palavra resumo.

3 Para melhor esclarecimento e maior discussão acerca das definições, cf. MOZZILLO, 2001 e MEGALE, 2005. 
Quadro 1: Dimensóes de bilinguismo propostas por Hamers.

\begin{tabular}{|c|c|c|c|c|}
\hline DiMENSÓES & \multicolumn{2}{|c|}{ DENOMINAÇÁo } & \multicolumn{2}{|c|}{ DEFINIÇÃo } \\
\hline \multirow{2}{*}{$\begin{array}{l}\text { Competência } \\
\text { relativa }\end{array}$} & \multicolumn{2}{|c|}{ Bilinguismo balanceado } & \multicolumn{2}{|c|}{$\mathrm{L} 1=\mathrm{L} 2$} \\
\hline & \multicolumn{2}{|c|}{ Bilinguismo dominante } & \multicolumn{2}{|c|}{$\mathrm{L} 1>\mathrm{L} 2$ ou $\mathrm{L} 1<\mathrm{L} 2$} \\
\hline \multirow{6}{*}{$\begin{array}{l}\text { Organização } \\
\text { cognitiva }\end{array}$} & \multicolumn{2}{|c|}{ Bilinguismo composto } & \multicolumn{2}{|c|}{ Uma representação para duas traduções } \\
\hline & \multicolumn{2}{|c|}{ Bilinguismo coordenado } & \multicolumn{2}{|c|}{ Duas representações para duas traduções } \\
\hline & \multirow{2}{*}{$\begin{array}{l}\text { Bilinguismo } \\
\text { infantil }\end{array}$} & Simultâneo & \multirow{2}{*}{$\begin{array}{c}\text { L2 adquirida antes dos } \\
10-11 \text { anos }\end{array}$} & $\begin{array}{l}\text { L1 e L2 adquiridas } \\
\text { ao mesmo tempo }\end{array}$ \\
\hline & & Consecutivo & & $\begin{array}{c}\mathrm{L} 2 \text { adquirida } \\
\text { posteriormente a } \mathrm{L} 1\end{array}$ \\
\hline & \multicolumn{2}{|c|}{ Bilinguismo adolescente } & \multicolumn{2}{|c|}{ L2 adquirida entre 11 e 17 anos } \\
\hline & \multicolumn{2}{|c|}{ Bilinguismo adulto } & \multicolumn{2}{|c|}{ L2 adquirida após 17 anos } \\
\hline \multirow{2}{*}{$\begin{array}{c}\text { Presença da } \\
\text { L2 }\end{array}$} & \multicolumn{2}{|c|}{ Bilinguismo endógeno } & \multicolumn{2}{|c|}{ Presença de L2 na comunidade } \\
\hline & \multicolumn{2}{|c|}{ Bilinguismo exógeno } & \multicolumn{2}{|c|}{ Ausência de L2 na comunidade } \\
\hline \multirow{2}{*}{$\begin{array}{l}\text { Status das } \\
\text { línguas }\end{array}$} & \multicolumn{2}{|c|}{ Bilinguismo aditivo } & \multicolumn{2}{|c|}{ Não há perda ou prejuízo da L1 } \\
\hline & \multicolumn{2}{|c|}{ Bilinguismo subtrativo } & \multicolumn{2}{|c|}{ Há perda ou prejuízo da L1 } \\
\hline \multirow{4}{*}{$\begin{array}{l}\text { Identidade } \\
\text { cultural }\end{array}$} & \multicolumn{2}{|c|}{ Bilinguismo bicultural } & \multicolumn{2}{|c|}{ Identificação positiva com dois grupos } \\
\hline & \multicolumn{2}{|c|}{ Bilinguismo monocultural } & \multicolumn{2}{|c|}{ Identidade cultural referente à L1 ou à L2 } \\
\hline & \multicolumn{2}{|c|}{ Bilinguismo acultural } & \multicolumn{2}{|c|}{ Identidade cultural referente apenas à L2 } \\
\hline & \multicolumn{2}{|c|}{ Bilinguismo decultural } & \multicolumn{2}{|c|}{ Sem identidade cultural } \\
\hline
\end{tabular}

Fonte: adaptado de MEGALE (2005, p. 6).

Para elucidar a relação entre bilinguismo e construção identitária, é válido mencionar o entendimento dos termos bilíngue bicultural, bilíngue monocultural, bilíngue acultural e bilíngue decultural, conforme a proposta de $\mathrm{Ha}$ mers e Blanc (2000). Para esses autores, de acordo com o critério de identidade cultural do individuo bilingue, um bilíngue bicultural é aquele que se identifica de forma positiva com dois grupos culturais distintos, os quais o reconhecem como falante. Ressalte-se, ainda, que nesses casos há um bilinguismo balanceado normalmente acompanhado de biculturalismo balanceado; no entanto, essa não é uma relação necessária. O bilíngue monocultural é aquele indivíduo que tem sua identidade cultural atrelada apenas a um grupo das duas línguas que utiliza. Contudo, caso esse bilíngue renuncie à identidade ligada à língua materna e se identifique com a cultura do grupo de sua L2, configurará, assim, 
o bilíngue acultural. Em contrapartida, pode ocorrer de o bilíngue renunciar à identidade de sua língua materna e também renunciar à identidade cultural de sua segunda língua, caracterizando, desse modo, o bilíngue decultural.

Assim como faz Megale (2009), cabe questionar se um bilíngue é necessariamente bicultural e se monolíngues pertencem apenas a uma cultura, enquanto bilíngues pertencem a duas. A autora argumenta:

de acordo com Grosjean (1982:157), algumas pessoas que utilizam duas línguas cotidianamente são, na verdade, monoculturais. De outra feita, uma pessoa monolíngue pode ser bicultural, como é o caso de um escocês falante da língua inglesa. Hamers e Blanc (2000:119) explicam que a relação entre bilinguismo, escolha da língua e identidade cultural em indivíduos bilíngues é muito complexa e depende de diversos fatores, havendo indícios de que experiências bilíngues na primeira infância influenciam o desenvolvimento da identidade cultural (MEGALE, 2009, p. 91).

De acordo com o exposto, percebe-se que, para classificar o tipo de bilinguismo, certas dimensóes (entre outras não apresentadas aqui) devem ser levadas em consideração. Neste artigo, a pretensão é a de explanar alguns dos aspectos envolvidos na constituição identitária de bilíngues (não importando o nível de proficiência na L2) cuja identidade cultural é referente apenas a um grupo das duas línguas que ele utiliza, (logo, sujeitos do bilinguismo monocultural).

Como bem sinaliza Rodrigues (2012, p. 363), "uma vez que exista um elo entre língua e identidade, a atitude linguística há de se manifestar no comportamento dos indivíduos em relação não apenas a essas línguas, mas também em relação a seus usuários". A relação entre língua e identidade se manifesta nas atitudes dos indivíduos em relação a essas línguas e seus usuários: atitudes que refletem o imaginário e as representaçóes que cada grupo tem da língua do outro. De acordo com Megale (2009, p.94), "quando pelo menos duas línguas estão em contato na sociedade, relaçóes de poder entre os grupos etnolinguísticos influenciarão o desenvolvimento da identidade cultural $\mathrm{da}$ criança”, e, portanto, em todo contato entre línguas haverá uma identidade em construção. Para melhor entendimento, os conceitos de identidade/construção de identidade, linguagem e cultura serão abordados no tópico a seguir. 


\section{Linguagem e identidade}

Para elencar os aspectos envolvidos na constituição identitária de bilíngues, torna-se necessário traçar um breve panorama dos Estudos Culturais, especificamente no que tange às questóes identitárias. Dessa forma, o conceito $^{4}$ de linguagem defendido é de acordo com a virada cultural/virada linguística.

Os Estudos Culturais (doravante EC) surgiram em virtude de um processo de mudança advindo de certos grupos sociais e são constituídos de diferentes ideias, métodos e teorias que giram em torno de um eixo central: a preocupação com o uso da cultura pelo povo. Basicamente, a cultura é estudada como sendo espaço de luta entre diversas outras culturas vinculadas em diferentes níveis da sociedade. De acordo com essa visão, o povo é visto como receptor, mas também como produtor da cultura, não sendo totalmente submisso à esfera econômica. A partir dos EC, há uma concepçáo particular de cultura, vista como um fenômeno heterogêneo, ativo e intervencionista. A linguagem tem um papel importante nessa visão e, desse modo, está intimamente ligada à virada cultural.

Segundo Hall (1997, p. 27), a virada cultural "refere-se a uma abordagem da análise social contemporânea que passou a ver a cultura como uma condiçâao constitutiva da vida social, ao invés de uma variável dependente". Antes dessa virada, entendia-se a linguagem (que constituiria assunto de interesse apenas dos especialistas nessa área, os linguistas e literatos) como subordinada e a serviço da realidade, e haveria modelos preexistentes a qualquer tipo de descriçáo. Ou seja, a linguagem era vista como um meio de comunicação entre os sujeitos, e serviria para relatar e denominar os fatos e objetos (realidade) que existiam no mundo.

Com a virada cultural, a linguagem tem sua compreensão ampliada, já que a maneira como vivemos e a razão daquilo que somos - nossas identidades - são compreendidas como práticas discursivas (HALL, 1997). De acordo com Hall, a formação das nossas identidades se dá culturalmente. Quer dizer:

4 O grifo serve para esclarecer que não se trata de um conceito único, fechado e correto. A linguagem, a partir desse marco, tem sua noção ampliada sem que seja una, pois não há uma verdade absoluta. Stuart Hall observa que a contribuição de Foucault (1970/1980) foi crucial para a "virada cultural": os Estudos Culturais não pretendem "[...] substituir um tipo de reducionismo (idealismo) por outro (materialismo), mas forçar-nos a repensar radicalmente a centralidade do cultural e a articulação entre os fatores materiais e culturais ou simbólicos na análise social. Este é o ponto de referência intelectual a partir do qual os estudos culturais se lançaram" (HALL, 1997, p. 32). 
tal formação é uma escolha pessoal que, no entanto, é feita pela "mediação de aspectos objetivos presentes nas normas, nas instituiçóes, nas atividades [...] nas açóes e estruturas sociais contextualizadas em um determinado tempo e lugar” (apud SANTOS, 2003, p. 2). Ainda segundo Hall (1997, p. 26-27),

[...] devemos pensar as identidades sociais como construídas no interior da representação, através da cultura, não fora delas. Elas são o resultado de um processo de identificação que permite que nos posicionemos no interior das definiçóes que os discursos culturais (exteriores) fornecem ou que nos subjetivemos (dentro deles). Nossas chamadas subjetividades são, então, produzidas parcialmente de modo discursivo e dialógico.

No caso de identidades nacionais e/ou regionais, por exemplo, o processo de identificação é estabelecido por uma marcação simbólica em relação a outras identidades - hino, costumes, práticas culturais, indumentária, culinária, entre outros aspectos (FREITAS, 2013, p. 13). De acordo com Said (1990, apud FREITAS, 2013, p. 14), "as fronteiras geográficas acompanham as sociais, étnicas e culturais de um modo previsível” e, portanto, as fronteiras geográficas, mesmo que simbolicamente, também são uma forma de marcação de identidades que, consequentemente, geram um tipo de exclusão social. Portanto, a linguagem constitui os sujeitos, cujas identidades são construídas por meio de atos linguísticos, como narrativas.

Além disso, é importante ressaltar os significados do termo identidade: Hall (2000) aponta que o conceito de identidade é estratégico e posicional. Isso quer dizer que a concepção de identidade não é imutável; "as identidades não são nunca unificadas [...] elas são multiplamente construídas ao longo de discursos, práticas e posições que podem se cruzar ou ser antagônicos. As identidades estão sujeitas a uma historicização radical, estando constantemente em processo de mudança e transformação" (HALL, 2000, p. 108). Para o autor, em relação à produção de identidades nacionais na pós-modernidade,

uma cultura nacional é um discurso - um modo de construir sentidos que influencia e organiza tanto nossas açóes quanto a concepção que temos de nós mesmos. As culturas nacionais, ao 
produzir sentidos sobre a nação, sentidos com os quais podemos nos identificar, constroem identidades. Esses sentidos estão contidos nas estórias que são contadas sobre a nação, memórias que conectam seu presente com seu passado e imagens que dela săo construídas (HALL, 1997, p. 55, grifo do autor).

Dessa forma, pode-se afirmar que os sujeitos estão em constante transformação de suas identidades, as quais são construídas por todo e qualquer discurso. Silva (2000, p. 97) corrobora essa concepção ao mencionar que "a identidade é instável, contraditória, fragmentada, inconsistente, inacabada. A identidade está ligada a estruturas discursivas e narrativas”. A partir dos discursos proferidos, portanto, estão sendo (re)constituídas as identidades de cada sujeito. De acordo com esse sucinto panorama, nos próximos tópicos será apresentado um paralelo entre as questôes identitárias e o bilinguismo.

\section{Reflexões finais acerca do bilinguismo e da construção de identidades}

Feitas as considerações, pode-se mensurar a tensão que há na relação entre o bilinguismo e a construçâo da identidade cultural, já que é a partir de discursos produzidos que o sujeito constitui sua identidade, independentemente da língua utilizada. Para além das questôes entre linguagem e identidade já comentadas, há um fator tênue, porém de grande importância nessa relação: a questão cultural intrínseca às questôes linguísticas. O aparato cultural e a marcação simbólica estão atrelados à utilização de uma L2. Conforme já apontado, Grosjean (1982, apud MEGALE, 2009, p. 91) considera que muitos bilíngues são monoculturais - e que muitos monolíngues podem ser biculturais.

O que leva um sujeito a ser mono ou bicultural, então, é justamente a identificação com um dos grupos culturais com que ele tem contato - seja o da L1 ou o da L2. A identificação se dá pela marcação da identidade e da diferença, e, nesses casos, a representação cultural de determinado grupo faz com o que o indivíduo, bilíngue ou não, se identifique e se construa como pertencente a este grupo. É evidente que, em comparação a um monolíngue, um bilíngue tem mais oportunidades de interagir pessoalmente com diferentes grupos culturais, conhecendo-os de maneira mais autêntica. Todavia, em 
virtude da globalização e do acesso quase instantâneo a diferentes culturas, o sujeito que utiliza uma única língua também tem grandes chances de se identificar com um ou mais grupos culturais distintos, uma vez que a constituição de uma identidade é feita a partir de várias narrativas - narrativas estas presentes nos meios de comunicação e interação virtual, por exemplo.

Embora não tenha sido apresentada nenhuma análise de dados, pode-se inferir que o contato entre duas ou mais línguas por um mesmo indivíduo leva ao questionamento da própria identidade, bem como à construção da identidade enquanto sujeito social. O bilíngue tem a oportunidade de se constituir enquanto sujeito em uma ou outra língua, valendo-se de representaçôes e de identificações. Todavia, a afirmação de identidade em LE dá-se por um processo conflituoso, já que, muitas vezes, o bilíngue questiona suas próprias convicções de forma não natural e harmoniosa. De acordo com Nascimento (2008, p. 154), "uma LE é sempre um lugar de conflito, de questionamentos identitários, através da confrontaçâo com o novo, com o diferente, com o outro". Segundo Almeida Filho (2002, apud NASCIMENTO, 2008, p. 151), durante o contato com uma L2, o sujeito "vai [se] constituindo e acrescentando novos aspectos à sua identidade.” Hall (2011, p. 12-13) esclarece que "a identidade torna-se uma celebração móvel: formada e transformada continuamente em relação às formas pelas quais somos representados ou interpelados nos sistemas culturais que nos rodeiam". Desse modo, uma L2 enquanto sistema cultural é parte integrante do processo de constituição identitária.

Para provocar possíveis novas discussóes, em relação à construção de conhecimentos em LE, vale salientar que existem inúmeros aspectos culturais envolvidos nas instâncias sociais para além do ensino/aprendizagem. Conforme ressalta Silva (1995b, p. 190), "é importante colocar no próprio centro do currículo uma visão que destaque o papel da linguagem e do discurso na produção de subjetividades particulares e identifique suas conexôes com desejos e vontades de poder - de indivíduos e grupos particulares".

\section{Referências}

COSTA, Marisa Vorraber; SILVEIRA, Rosa Maria Hessel; SOMMER, Luis Henrique. Estudos Culturais, Educação e Pedagogia. Revista Brasileira de Educação, n. 23: 36 - 61. maio/ago, 2003. 
FLORY, Elizabete Villibor; SOUZA, Maria Thereza Costa Coelho de. Bilinguismo: Diferentes definiçóes, diversas implicaçóes. Revista Intercâmbio, v. XIX: 23 - 40, São Paulo: LAEL/PUC-SP, 2009.

FREITAS, Letícia Fonseca Richthofen de. Práticas identitárias e a construção das alteridades no contexto escolar. In: FERREIRA, Taís (Org.). Identidades no contexto escolar. Porto Alegre: Observatório Gráfico, 2013. p. 11 - 25.

GROSJEAN, François. Individual Biligualism. In: The Encyclopedia of Language and Linguistics. Oxford: Pergamon Press, 1994.

HALL, Stuart. A centralidade da cultura: notas sobre as revoluçóes do nosso tempo. Educação \& Realidade, v. 22, n.2: 15 - 46, Porto Alegre/RS: UFRGS/ FACED, jul./dez. 1997.

. A identidade cultural na pós-modernidade. $11^{\mathrm{a}}$ ed. Rio de Janeiro: DP\&A, 2011.

. Quem precisa de identidade? In: SILVA, Tomaz Tadeu da. (Org.) Identidade e diferença: a perspectiva dos estudos culturais. Petrópolis/RJ: Vozes, 2000. p.103-133.

HAMERS, Josiane F.; BLANC, Michel A. Bilinguality and Bilingualism. $2^{\text {nd }}$ edition. Cambridge: Cambridge University Press, 2000.

MEGALE, Antonieta Heyden. Bilingüismo e educação bilíngüe - discutindo conceitos. Revista Virtual de Estudos da Linguagem - ReVEL. v. 3, n. 5: 1 - 13, ago. 2005.

. Duas línguas, duas culturas? A construção da identidade cultural de indivíduos bilíngues. Veredas, v. 2, n. 9: 90 - 102, 2009.

MOZZILLO, Isabella. A conversação bilíngüe dentro e fora da sala de aula de língua estrangeira. In: HAMMES, W.; VETROMILLE-CASTRO, R. (Orgs.) Transformando a sala de aula, transformando o mundo: ensino e pesquisa em língua estrangeira. Pelotas: Educat, 2001.

NASCIMENTO, Cecília Eller Rodrigues. O jogo na aula de língua estrangeira: espaço aberto para a manifestação do eu. Alfa, v. 52, n. 1: 149 - 156, São Paulo, 2008.

RODRIGUES, Luiz Carlos Balga. Atitude, imaginário, representação e identidade linguística: aspectos conceituais. Cadernos do XIV Congresso Nacional de Linguistica e Filologia/Círculo Fluminense de Estudos Filológicos e Linguisticos, v. XVI, n. 4, t. 1: 362 - 372, Rio de Janeiro: Uerj, 2012.

SANTOS, João de Deus dos. A centralidade da cultura: notas sobre as revoluçóes do nosso tempo [resenha]. Revista Brasileira de Educação, <http://www. scielo.br/pdf/rbedu/n23/n23a12.pdf, 28/09/2013. 
SILVA, Tomaz Tadeu da. A produção social da identidade e da diferença. In: . (Org.) Identidade e diferença: a perspectiva dos estudos culturais. Petrópolis/RJ: Vozes, 2000. p.73-102.

SILVA, Tomaz Tadeu da. Currículo e Identidade Social: territórios contestados. In: . (Org.) Alienígenas na sala de aula: uma introdução aos estudos culturais em educação. Petrópolis/RJ: Vozes, 1995ª p. 190-207.

SILVA, Tomaz Tadeu da. Os novos mapas culturais e o lugar do currículo numa paisagem pós-moderna. In: - (Org.) Territórios contestados: o currículo e os novos mapas políticos e culturais. Petrópolis/RJ: Vozes, $1995 \mathrm{~b}$. p. 184-202.

SILVA, Tomaz Tadeu da. O currículo como fetiche: a poética e a política do texto curricular. Belo Horizonte: Autêntica, 1999.

TUSSI, Matheus Gazzola; XIMENEZ, Andrey. Bilinguismo: características e relação com aspectos cognitivos. Anais da X Semana de Letras. Porto Alegre: EdiPUC RS, 2010, <http://ebooks.pucrs.br/edipucrs/anais/Xsemanadeletras/ comunicacoes/Matheus-Gazzola-Tussi.pdf>, 13/01/2014.

\title{
BILINGUALISM AND IDENTITY: A DUAL CONSTRUCTION
}

\begin{abstract}
This article proposes a brief discussion about the constitution of bilingual subjects' identity. We do not aim to present data from field research, neither to make a deep analysis of the discussed concepts. Our goal, therefore, is to think, under the perspective of Cultural Studies, about the complexity and the tensions involved in the issue of bilingual's identity.
\end{abstract}

KEYWORDS: Identity Constitution; Bilingualism; Linguistic Identity.

Recebido em: 18/04/2016 Aprovado em: 18/10/2016 